\section{Stepwise synthesis of sandwich-structured composite zeolite membranes with enhanced separation selectivity $\dagger$}

\author{
Aisheng Huang,* Nanyi Wang and Jürgen Caro \\ Received 21st November 2011, Accepted 18th February 2012 \\ DOI: $10.1039 / \mathrm{c} 2 \mathrm{cc} 17248 \mathrm{~h}$
}

Sandwich-structured composite zeolite membranes with enhanced hydrogen selectivity were prepared on porous $\alpha-\mathrm{Al}_{2} \mathrm{O}_{3}$ supports by using 3-aminopropyltriethoxysilane as an interlayer.

Membrane-based separations can be energy and investment effective in comparison with conventional separation processes like distillation and adsorption. Due to their uniform pore structure and high thermal stability, supported zeolite membranes have attracted much attention in single gas permeation and mixed gas separation. ${ }^{1-3}$ So far, various types of supported polycrystalline zeolite membranes, typically MFI, ${ }^{4,5}$ LTA $^{6-10}{ }^{6 D R},{ }^{11,12} \mathrm{CHA}^{13,14} \mathrm{AFI}^{15}$ and FAU, ${ }^{16,17}$ have been reported. Among these molecular sieve membranes, the 12-membered hydrophilic zeolite FAU membrane is of high interest in potential applications such as solvent dehydration, organic liquids separation and membrane catalysis. In the past two decades, many research efforts have been directed on the synthesis of dense and phase-pure zeolite FAU membranes. ${ }^{16-24}$ But it is found that it is extremely difficult to form a FAU molecular sieve membrane because of the poor heterogeneous nucleation of FAU on the support surface. ${ }^{19,20}$ Therefore, seed-coating of the supports is usually indispensable to offer nucleation centers to promote nucleation and secondary growth of the FAU layer. ${ }^{21-24}$ Applying the secondary growth method, several techniques for the attachment of zeolite seeds onto the support surface have been developed, including rub-coating, ${ }^{16}$ dip-coating ${ }^{21}$ and electrostatic attraction ${ }^{22}$ with FAU seeds. The secondary growth method exhibits many advantages such as better control of membrane microstructure and orientation. ${ }^{25}$ However, the development of a reliable and powerful seeding technique is still highly desired for large-scale membrane synthesis. ${ }^{26}$

Recently, we have developed a seeding-free strategy for the preparation of zeolite FAU molecular sieve membranes by using APTES as a covalent linker between the zeolite membrane and the porous $\mathrm{Al}_{2} \mathrm{O}_{3}$ support. ${ }^{27}$ Due to their

Institute of Physical Chemistry and Electrochemistry,

Leibniz University Hannover, Callinstraße 3-3A, D-30167 Hannover, Germany.E-mail: aisheng.huang@pci.uni-hannover.de;

Fax: + 49-511-762 1912; Tel: + 49-511-762 2125

$\dagger$ Electronic supplementary information (ESI) available: Experimental details, SEM, XRD, measurement equipment and gases permeances. See DOI: $10.1039 / \mathrm{c} 2 \mathrm{cc} 17248 \mathrm{~h}$

rather large pore size of $0.74 \mathrm{~nm}$, zeolite FAU membranes are not the perfect candidates for the separation of small molecules by molecular sieving. Thus, novel zeolite FAU/LTA composite membranes which consist of a FAU layer on a small pore LTA zeolite layer are expected to improve the separation selectivity of zeolite membranes.

To date, only a few two- or multi-layered zeolite membranes have been reported. In 2000, Salomón et al. synthesized a MOR-ZSM-5-CHA composite membrane to selectively remove water from the reaction atmosphere during the gas-phase synthesis of methyl-tert-butyl ether (MTBE) from tert-butanol and methanol. ${ }^{28} \mathrm{Li}$ et al. reported zoned MFI films consisting of a silicalite- 1 and ZSM-5 layer. ${ }^{29}$ Zhang et al. synthesized a two-layered zeolite NaA-silicalite-1 membrane on a porous aluminium tube by using a secondary growth synthesis method. ${ }^{30}$ Iglesia et al. prepared bi-functional H-ZSM-5-MOR composite membranes thus combining the catalytic activity of H-ZSM-5 with the water pervaporation selectivity of MOR membranes. ${ }^{31}$ To the best of our knowledge, however, there are no reports on gas separation of composite zeolite membranes.

In the present work, we report a stepwise synthesis strategy to prepare sandwich-structured LTA-FAU composite membranes to enhance the separation selectivity by using APTES as an interlayer between the LTA and FAU layers as well as between the alumina support and the zeolite LTA layer, as shown in Fig. 1. The zeolite LTA membrane, with a relatively small pore size of about $0.4 \mathrm{~nm}$, is expected to be a candidate for the separation of small sized molecules such as $\mathrm{H}_{2}$ and $\mathrm{CO}_{2},{ }^{6-10}$ while the zeolite FAU membrane with a larger pore size will not reduce the permeation flux like the narrower LTA layer. Further, the composition difference between the zeolite

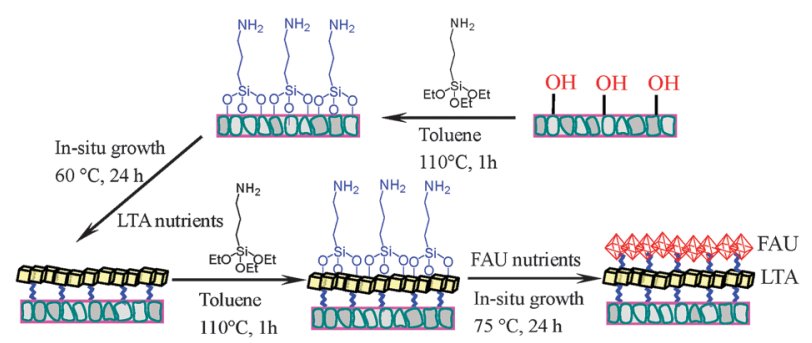

Fig. 1 Schematic diagram for stepwise synthesis of a sandwichstructured zeolite LTA-FAU composite membrane by using APTES as an interlayer. 

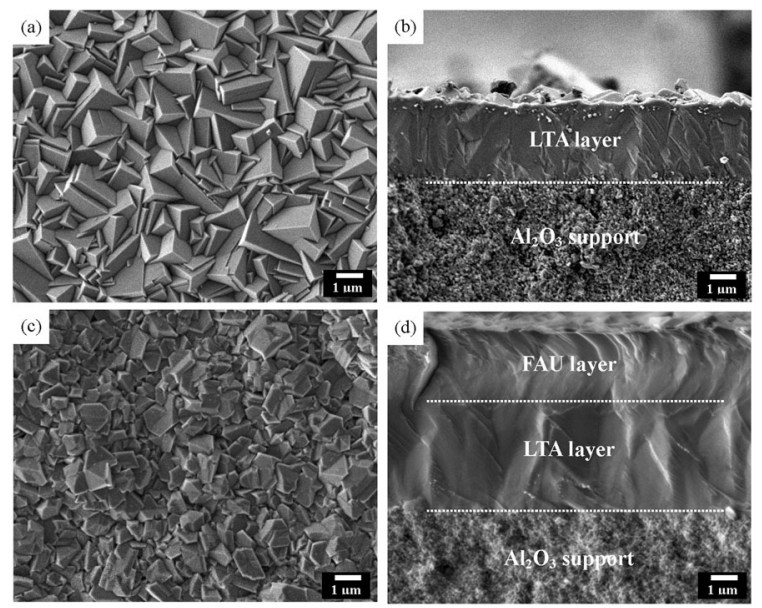

Fig. 2 Top view (a) and cross-section view (b) SEM images of the LTA bottom layer prepared on APTES functionalized $\mathrm{Al}_{2} \mathrm{O}_{3}$ support; top view (c) and cross-section view (d) SEM images of LTA-FAU composite membranes on APTES functionalized $\mathrm{Al}_{2} \mathrm{O}_{3}$ support.

LTA and FAU layers is relatively small and both of them have strong hydrophilicity due to their low $\mathrm{Si} / \mathrm{Al}$ ratio. Therefore, it can be expected that sandwich-structured composite LTA-FAU membranes will be formed and show higher gas separation performances than the corresponding single phase zeolite membranes.

Fig. 2a shows the SEM top view of the zeolite LTA bottom layer on the APTES-functionalized asymmetric $\alpha-\mathrm{Al}_{2} \mathrm{O}_{3}$ supports. In good agreement with our previous report, ${ }^{32}$ the support surface is completely covered by a layer of uniform and compact cubic-shaped crystals, and no visible cracks, pinholes or other defects can be observed. From the crosssection view shown in Fig. $2 b$, it can be seen that the LTA bottom layer is well intergrown with the support and has a thickness of about $3.5 \mu \mathrm{m}$. The formation of phase pure zeolite LTA bottom layers with a high degree of crystallinity was confirmed by the XRD pattern as shown in Fig. S1c (ESI $\dagger$ ), which indicates that all peaks match well with those of LTA zeolite besides the $\mathrm{Al}_{2} \mathrm{O}_{3}$ signals from the support. Fig. 2c shows the SEM top view of the zeolite FAU top layer on the previously made LTA bottom layer. It can be seen that a well intergrown FAU layer with typical bi-pyramidal morphology is formed by using APTES as an interlayer between the LTA and FAU layers. A sandwich-structured LTA-FAU composite membrane is observed from the cross-section view (Fig. 2d; Fig. S3 (ESI $\dagger)$ ). The successful preparation of core (LTA)-shell (FAU) composite crystals (Fig. S4, ESI $\dagger$ ) further confirms that consecutive LTA-FAU layers can be prepared by using APTES as an interlayer.

The formation of a double LTA-FAU layer is confirmed by EDXS analysis. Fig. 3 shows the evolution of the $\mathrm{Si} / \mathrm{Al}$ ratio of the cross-section of the LTA-FAU composite membrane calculated with the atomic amounts derived from the $\operatorname{SiK} \alpha$ and $\mathrm{AlK} \alpha$. The $\mathrm{Si} / \mathrm{Al}$ ratio decreases from the external zeolite FAU top layer, and the LTA layer to the $\mathrm{Al}_{2} \mathrm{O}_{3}$ support. A Si/Al ratio of $\sim 1.8$ for the FAU layer and a $\mathrm{Si} / \mathrm{Al}$ ratio of $\sim 1.0$ for the LTA layer can be derived.

It is found that the APTES treatment of the as-made LTA bottom layer is vital to prepare the following FAU layer.
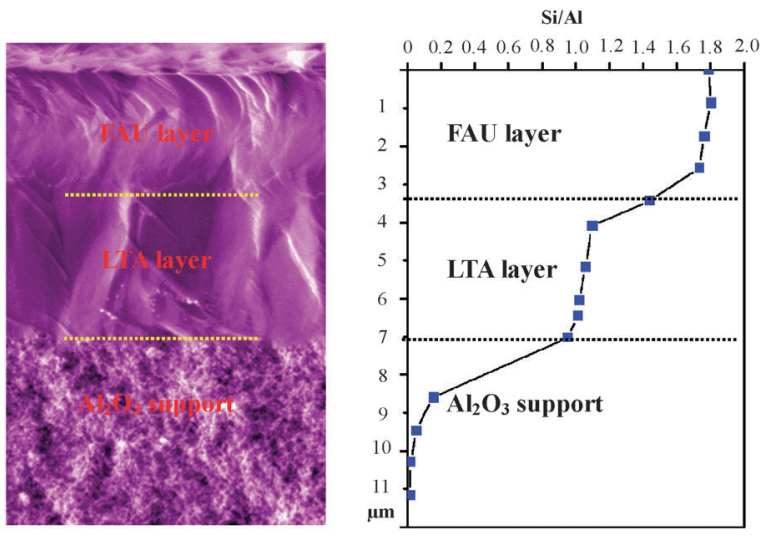

Fig. 3 Evolution of $\mathrm{Si} / \mathrm{Al}$ ratio of the cross-section of the LTA-FAU composite membrane calculated with the atomic amounts derived from the $\operatorname{SiK} \alpha$ and $\mathrm{AlK} \alpha$.

No FAU layer can be formed on the as-made zeolite LTA bottom layer without APTES treatment. For extended synthesis times, a remarkable dissolution of the LTA bottom layer is observed without APTES treatment which results in a rough surface (Fig. S5, ESI $\dagger$ ). As reported previously, ${ }^{33}$ repeated synthesis stages resulted in the dissolution and transformation of the zeolite LTA layer. Obviously, APTES acts as a protective barrier and avoids the degradation of the as-made LTA layer during the following hydrothermal FAU synthesis. Besides zeolite LTA-FAU composite membranes, the presented strategy to use APTES as an interlayer works well to prepare other sandwich-structured composite membranes like FAU-LTA (Fig. S6), LTA-LTA (Fig. S7), and FAU-FAU (Fig. S8) (ESI $\dagger)$. This concept will open a new door to prepare multifunctional zeolite layers used for catalytic membrane reactors.

The zeolite membranes were evaluated in single gas permeation and mixed gas separation. The volumetric flow rates of the single gases $\mathrm{H}_{2}, \mathrm{CO}_{2}, \mathrm{~N}_{2}, \mathrm{CH}_{4}$ and $\mathrm{C}_{3} \mathrm{H}_{8}$ as well as of the equimolar binary mixtures $\mathrm{H}_{2} / \mathrm{CO}_{2}$ were measured using the Wicke-Kallenbach technique (Fig. S9, ESI $\dagger$ ). Fig. 4 shows the permeances of the single gases through the LTA-FAU composite membrane as well as the single zeolite LTA and

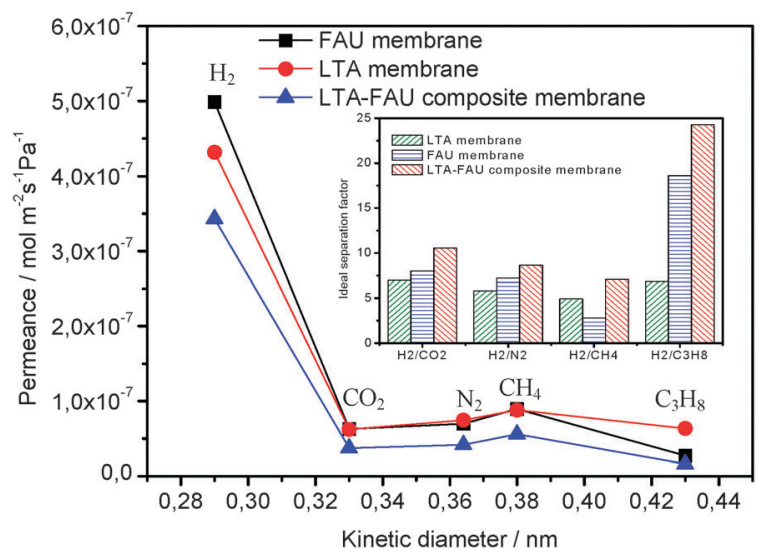

Fig. 4 Single gas permeances of different gases through the LTA-FAU composite membrane as well as the single zeolite LTA and FAU membranes, at $100{ }^{\circ} \mathrm{C}$ and 1 bar pressure difference as a function of the gas kinetic diameter. The inset shows the ideal separation factors of the membranes for $\mathrm{H}_{2}$ over other gases. 
FAU membranes at $100{ }^{\circ} \mathrm{C}$ and 1 bar pressure difference as a function of the gas kinetic diameters of the permeating molecules. As shown in Fig. 4, $\mathrm{H}_{2}$ has the highest permeance for all membranes under study due to its smallest kinetic diameter of $0.29 \mathrm{~nm}$. As expected, the single gas permeances through the LTA-FAU composite membrane are slightly lower than those through the single zeolite LTA or FAU membranes. At $100^{\circ} \mathrm{C}$ for the LTA-FAU composite membrane, the ideal separation factors of $\mathrm{H}_{2}$ from $\mathrm{CO}_{2}, \mathrm{~N}_{2}, \mathrm{CH}_{4}$ and $\mathrm{C}_{3} \mathrm{H}_{8}$ are 10.6, 8.6, 7.1, 24.3 , respectively, which not only exceed the corresponding Knudsen coefficients (4.7, 3.7, 2.8 and 4.7 respectively) but are also higher than the corresponding ideal separation factors of the single phase zeolite LTA (7.0, 5.8, 4.9 and 6.8) and FAU (8.0, 7.2, 5.6 and 18.6) membranes, suggesting that the LTA-FAU composite membrane displays a higher hydrogen selectivity. The enhancement of the separation performance is probably attributed to the novel sandwich structure of zeolite membranes by using APTES as an interlayer. The functionalization of APTES is helpful to promote the nucleation and growth of a dense zeolite layer, ${ }^{27,32}$ and the following secondary growth of the double zeolite layer can increase the membrane density to reduce the inter-crystalline defects.

The molecular sieve performance of the zeolite LTA-FAU composite membrane was confirmed by the separation of the equimolar mixture $\mathrm{H}_{2} / \mathrm{CO}_{2}$ at $100{ }^{\circ} \mathrm{C}$ and 1 bar. As shown in Fig. S10 and Table S1 (ESI $\dagger$ ), for the $1: 1 \mathrm{H}_{2} / \mathrm{CO}_{2}$ mixtures, the mixture separation factor $\mathrm{H}_{2} / \mathrm{CO}_{2}$ determined as the molar ratio in permeate and retentate is 8.2 , which is higher than that of the single phase zeolite LTA membrane (5.2) and single zeolite FAU membrane (6.6). The as-made LTA-FAU composite zeolite membranes have been tested for the separation of $\mathrm{H}_{2} / \mathrm{CO}_{2}$ at $150{ }^{\circ} \mathrm{C}$ for $48 \mathrm{~h}$, and both selectivity and permeance remained unchanged (Fig. S11, ESI $\dagger$ ). Further, the enhancement of $\mathrm{H}_{2} / \mathrm{CO}_{2}$ selectivity has been reproduced for other three composite membranes, and for all of them the $\mathrm{H}_{2} / \mathrm{CO}_{2}$ selectivities are higher than those of the single phase zeolite membranes, i.e., the $\mathrm{H}_{2} / \mathrm{CO}_{2}$ selectivities of FAU-LTA, LTA-LTA and FAU-FAU are 8.3, 8.8 and 7.0. Obviously, the permeance of the membrane depends on the thickness of the corresponding membrane. As shown in Table S1 (ESI $\dagger$ ), the $\mathrm{H}_{2}$ permeability is comparable for FAU-LTA with LTA-FAU, LTA with LTA-LTA, and FAU with FAU-FAU membrane. More work is in progress to evaluate the details of the gas separation performances of these novel composite membranes.

In conclusion, in the present work, we have developed a facile and universal synthesis method to prepare sandwichstructured composite zeolite membranes by using APTES as an interlayer. Attributing to the covalent linkages with the surface hydroxyl groups, APTES can act as a molecular binder for attracting and anchoring the zeolite precursors onto the support surface to promote nucleation and growth. Further, the presence of APTES can provide a protective barrier to avoid the degradation of the as-made zeolite layer during the following hydrothermal synthesis, thus it is helpful for the formation of well intergrown sandwich-structured composite membranes. The composite zeolite membranes display higher separation selectivities than the corresponding single phase zeolite membranes. For LTA-FAU composite membranes at $100{ }^{\circ} \mathrm{C}$ and $1 \mathrm{bar}$, the single gas separation factors of $\mathrm{H}_{2} / \mathrm{CO}_{2}$, $\mathrm{H}_{2} / \mathrm{N}_{2}, \mathrm{H}_{2} / \mathrm{CH}_{4}$ and $\mathrm{H}_{2} / \mathrm{C}_{3} \mathrm{H}_{8}$ are 10.6, 8.6, 7.1, 24.3, which are higher than those from the corresponding Knudsen coefficients. Further, the enhancement of $\mathrm{H}_{2} / \mathrm{CO}_{2}$ mixture selectivity has also been reproduced for all the composite membranes.

Financial support by EU CARENA (FP7-NMP-2010LARGE-4, No. 263007) is acknowledged. Dr A. Feldhoff is thanked for support in electron microscopy.

\section{Notes and references}

1 J. Caro and M. Noack, Microporous Mesoporous Mater., 2008, $115,215$.

2 D. L. Gine and R. D. Noble, Science, 2011, 332, 674.

3 E. E. McLeary, J. C. Jansen and F. Kapteijn, Microporous Mesoporous Mater., 2006, 90, 198.

4 Z. Wang, H. Wang, A. Mitra, L. Huang and Y. Yan, Adv. Mater., 2001, 13, 746.

5 G. A. Ozin, A. Kuperman and A. Stein, Angew. Chem., Int. Ed. Engl., 1989, 28, 359.

6 X. Xu, W. Yang, J. Liu and L. Lin, Adv. Mater., 2000, 12, 195.

7 K. Aoki, K. Kusakabe and S. Morooka, J. Membr. Sci., 1998, 141, 197.

8 A. Huang, F. Liang, F. Steinbach, T. M. Gesing and J. Caro, J. Am. Chem. Soc., 2010, 132, 2140.

9 A. Huang and J. Caro, Chem. Commun., 2010, 46, 7748

10 A. Huang and J. Caro, Chem. Mater., 2010, 22, 4353.

11 M. Kanezashi, J. O'Brien-Abraham, Y. S. Lin and K. Suzuki, AIChE J., 2008, 54, 1478.

12 J. van den Bergh, W. Zhu, J. Gascon, J. A. Moulijn and F. Kapteijn, J. Membr. Sci., 2008, 316, 35.

13 M. A. Carreon, S. Li, J. L. Falconer and R. D. Noble, J. Am. Chem. Soc., 2008, 130, 5412.

14 M. A. Carreon, S. Li, J. L. Falconer and R. D. Noble, Adv. Mater., 2008, 20, 729 .

15 S. Mintova, S. Mo and T. Bein, Chem. Mater., 1998, 10, 4030.

16 K. Kusakabe, T. Kuroda, A. Murata and S. Morooka, Ind. Eng. Chem. Res., 1997, 36, 649.

17 V. Nikolakis, G. Xomeritakis, A. Abibi, M. Dickson, M. Tsapatsis and D. G. Vlachos, J. Membr. Sci., 2001, 184, 209.

18 B. H. Jeong, Y. Hasegawa, K. I. Sotowa, K. Kusakabe and S. Morooka, J. Chem. Eng. Jpn., 2002, 35, 167.

19 G. Zhu, Y. Li, H. Zhou, J. Liu and W. Yang, J. Membr. Sci., 2009, 337, 47.

20 G. Zhu, Y. Li, H. Zhou, J. Liu and W. Yang, Mater. Lett., 2008, 62, 4357.

21 H. Kita, T. Inoue, H. Asamura, K. Tanaka and K. Okamoto, Chem. Commun., 1997, 45.

22 M. Lassinantti, J. Hedlund and J. Sterte, Microporous Mesoporous Mater., 2000, 38, 25.

23 I. G. Giannakopoulos and V. Nikolakis, Ind. Eng. Chem. Res., 2005, 44, 226.

24 H. Kita, K. Fuchida, T. Horita, H. Asamura and K. Okamoto, Sep. Purif. Technol., 2001, 25, 261.

25 M. C. Lovallo and M. Tsapatsis, AIChE J., 1996, 42, 3020.

26 A. Huang, Y. S. Lin and W. S. Yang, J. Membr.Sci., 2004, 245, 41.

27 A. Huang, N. Wang and J. Caro, J. Membr. Sci., 2012, 389, 272.

28 M. A. Salomón, J. Coronas, M. Menéndez and J. Santamaría, Appl. Catal., A, 2000, 2000, 201.

29 Q. Li, J. Hedlund, J. Sterte, D. Creaser and A. J. Bons, Microporous Mesoporous Mater., 2002, 56, 291.

30 X. Zhang, H. Liu and K. L. Yeung, J. Phys. Chem. Solids, 2005, 66, 1034

31 Ó. de la Iglesia, S. Irusta, R. Mallada, M. Menéndez, J. Coronas and J. Santamaría, Microporous Mesoporous Mater., 2006, 93, 318.

32 A. Huang, F. Liang, F. Steinbach and J. Caro, J. Membr. Sci., $2010,350,5$.

33 X. Xu, W. Yang, J. Liu and L. Lin, Microporous Mesoporous Mater., 2001, 43, 299. 